\title{
CINE SIN CÁMARA EN LA UNIVERSIDAD: TEORÍA Y PRÁCTICA DE UN CINE HECHO A MANO
}

\author{
Albert Alcoz \\ Universitat de Barcelona. Departament d'Arts Visuals i Disseny
}

\section{Resumen}

Investigar el papel del cine sin cámara en el contexto universitario es el motivo principal de este artículo. Identificar la presencia, dentro de la academia, de una práctica fílmica estrechamente asociada a la experimentación cinematográfica; describir los diferentes planteamientos elaborados por el profesorado en un conjunto de facultades internacionales; visibilizar el rigor teórico y la articulación histórica que se despliegan en estas asignaturas; valorar la implicación del alumnado al trabajar imágenes artesanalmente condicionadas por un dispositivo tecnológico, son algunos de los argumentos desarrollados en el texto. Acercar la enseñanza del cine a su principal materia prima, el celuloide -en un momento en que este se encuentra desplazado progresivamente del audiovisual-es la razón de ser de un área de estudio generalmente asociada al cine libre y personal. Determinar su relevancia en la academia permite observar cómo su estudio y su puesta en práctica se formaliza tanto en el contexto artístico como en el fílmico.

\section{Palabras clave: CINE SIN CÁMARA; CINE DIRECTO; CINE HECHO A MANO; CINE DE ANIMACIÓN EXPERIMENTAL}

\section{CAMERALESS FILM AT THE UNIVERSITY: THEORY AND PRACTICE OF A HANDMADE CINEMA}

Abstract

Investigating the role of film without a camera in the university context is the main reason for this article. Some of the objectives developed in the text are to identify the presence within the academy of a film practice closely associated with film experimentation; to describe the different approaches developed by teachers in a set of international faculties; to make visible the theoretical rigor and historical articulation that are displayed in these subjects; and to recognize the involvement of students when working with handmade images, conditioned by a technological device. Bringing the teaching of cinema closer to its main raw material, celluloid -at a time when it is progressively displaced from digital media- is aim of an area generally associated with free and personal cinema. Determining its relevance in the academy allows us to observe how its study and its implementation is formalized in both artistic and filmic contexts.

\section{Keywords: CAMERALESS FILM; DIRECT CINEMA; HANDMADE CINEMA; EXPERIMENTAL ANIMATION}

\footnotetext{
Alcoz, Albert. 2020. "Cine sin cámara en la universidad: Teoría y práctica de un cine hecho a mano“. AusArt 8 (1): 77-90. D0I: 10.1387/ ausart.21497
}

\section{AUSART}


Dilucidar el papel que tiene un ámbito tan específico como el del cine sin cámara dentro de la enseñanza universitaria, es el propósito principal del texto que sigue a continuación. Para hacerlo se describe brevemente la tradición de esta práctica en la historia del cine, teniendo en cuenta su prolija vinculación con el cine de vanguardia y el experimental, así como sus incursiones puntuales en la industria audiovisual. Simultáneamente se detecta cómo el cine sin cámara halla una estrecha conexión con el denominado cine de animación experimental.

Para entender la presencia actual de este cine en los estudios universitarios se ha contado con la opinión de una serie de especialistas del ámbito español que imparten esta tendencia cinematográfica en Grados de Arte y Cine. La investigación incluye las reflexiones de cuatro artistas que combinan el desarrollo de su propia obra audiovisual con la enseñanza universitaria. Esperanza Collado, Alberto Cabrera Bernal, Laura Ginés y Marcel Pié imparten materias audiovisuales en las que describen modos directos de confeccionar imágenes en movimiento. Incorporando esta pluralidad de voces en esta breve investigación se visibiliza no sólo la resistencia de lo analógico frente a lo digital en el aprendizaje audiovisual, sino también cómo los soportes fílmicos contribuyen a ampliar el conocimiento sobre el arte cinematográfico.

La actualidad del cine sin cámara en la universidad evidencia la importancia que supone transmitir al alumnado unos conocimientos derivados de la vertiente fotoquímica del medio. Vislumbrar el valor de las múltiples técnicas artesanales que atesora este cine es una operación que demuestra la relevancia de lo analógico en un momento histórico marcado por la plena consolidación de lo digital en todas las vertientes del audiovisual. Es por ello que este tipo de aproximaciones promueven formalizaciones conceptuales que implican poder vehicular una conciencia crítica respecto al momento histórico actual. Más allá de la supuesta espontaneidad y ligereza del gesto artístico aplicado sobre el celuloide transparente, opaco o apropiado, el cine sin cámara fomenta discursos que revelan perspectiva histórica y conocimiento de causa. La puesta a punto del soporte fotoquímico, la materia fílmica principal, es el mínimo común denominador de unas asignaturas situadas entre la teoría y la práctica. 


\section{¿DE QUÉ HABLAMOS CUANDO NOS REFERIMOS AL CINE SIN CÁMARA?}

El cine sin cámara lo forman todas aquellas prácticas fílmicas realizadas directamente sobre el propio celuloide. Es una amplia área cinematográfica que identifica un extenso conjunto de técnicas de manipulación directa sobre película. Muchas de estas recogen la herencia de las artes gráficas y las artes visuales previas como son el dibujo y la pintura. Como su propio nombre indica, el cine sin cámara prescinde de cualquier tipo artilugio óptico de captación de imágenes fotoquímicas para su consecución. La herramienta que generalmente se asocia a la realización de imágenes en movimiento no tiene cabida en un cine que defiende la creación visual desde una perspectiva plástica elaborada manualmente. Trabajar con las manos es la estrategia principal de una práctica que estudia los diferentes mecanismos tecnológicos de los que participa el medio audiovisual para poder comprender su funcionamiento. Conocer las particularidades técnicas de los soportes fílmicos (con sus fotogramas, sus perforaciones laterales, su banda sonora óptica o magnética, su superficie, su flexibilidad) y su traducción a la pantalla tras el paso por el proyector, son cuestiones inherentes a la práctica del cine sin cámara. Comprender la idiosincrasia de cada uno de los formatos disponibles $(35 \mathrm{~mm}, 16$ $\mathrm{mm}, 8 \mathrm{~mm}, 9,5 \mathrm{~mm}$, super $8,70 \mathrm{~mm}$, etc.) y familiarizarse con los mecanismos de empalmadoras, moviolas y proyectores, son operaciones a asimilar para experimentar las técnicas del cine sin cámara. Todo ello no está exento de su posible digitalización final.

Este cine se puede ejercer sobre película transparente o película opaca pero también admite material previamente filmado. Es un ámbito derivado del found footage también designado como cine de metraje encontrado, cine de apropiación, de imágenes recicladas o robadas ${ }^{1}$. El trabajo manual sobre la superficie de la película es el método principal empleado en esta dimensión de la experimentación a menudo asociada con el cine de animación. Partiendo de la exploración inusitada de técnicas y materiales plásticos asociados a las artes gráficas, el cine sin cámara incorpora un sinfín de opciones estéticas que, muy a menudo, son el resultado de las investigaciones autodidactas de sus artífices; son procesos de investigación personal, producto del ensayo y el error. Las imágenes resultantes atesoran un elevado grado de libertad formal consecuencia del azar y la aleatoriedad. Es un cine manual que vislumbra tanto la destreza de los artistas a la hora de dibujar fotograma a fotograma, como el afán de curiosidad a la hora de generar nuevas configuraciones. 
Manipular y alterar las propiedades visuales de las imágenes en movimiento, empleando técnicas propias del cine sin cámara, son operaciones que se han llevado a cabo desde los inicios del cine. La coloración fotograma a fotograma y el proceso de tintado de escenas para dramatizar secuencias enteras filmadas en blanco y negro, se practican durante los primeros años del cinematógrafo. George Méliès y Segundo de Chomón son buenos ejemplos de esta tendencia primigenia derivada de la imposibilidad de filmar con película de color. Años después cineastas como el canadiense Norman McLaren y el neozelandés Len Lye desarrollan experimentaciones visuales situadas entre la figuración y la abstracción cuyos resultados se enmarcan dentro de la música visual (Brougher, Strick, Wiseman \& Zilczer 2005). El primero se concentra en manchas de colores dinámicos como en Begone Dull Care (1949) o en dibujos animados aplicados sobre los fotogramas en el caso de Blinkity Blank (1955) (Bakedano 1987). El segundo propone insólitas formalizaciones coloristas $-A$ Colour Box (1936) - o abstracciones lineales solucionadas mediante incisiones sobre emulsión opaca -Free Radicals (1958)-. Estos gestos artísticos producen películas pioneras que influyen en un gran número de artistas "interesados en explorar las cualidades del movimiento en un sentido general" (Furniss 1998, 41).

Dibujar, cincelar, rayar y pintar son algunas de las acciones que hacen centenares de cineastas interesados en explorar la magia del celuloide como un soporte estrecho y alargado -la cinta de la película-, finalmente ampliado -su traducción en la pantalla durante la proyección-2 ${ }^{2}$ Títulos paradigmáticos de la experimentación como Dog Star Man (1961-64) de Stan Brakhage y Ere erera baleibu icik subua aruaren... (1970) de José Antonio Sistiaga (Fig. 1) -primer largometraje enteramente realizado con las técnicas del cine sin cámara-, son algunas de las gemas de la aplicación pictórica sobre la emulsión. Otras piezas de estos mismos autores como Mothlight (1963) e Impresiones en la alta atmósfera (1989) innovan al jugar con la posibilidad del collage orgánico o con el uso del $70 \mathrm{~mm}$ (Artigas 1990).

Paolo Gioli, Caroline Leaf, Bärbel Neubauer, Helen Hill, Cécile Fontaine, Emmanuel Lefrant y Scott Fitzpatrick son algunas de las personas que parten del cine sin cámara para continuar desarrollando sus posibilidades estéticas. Las filmaciones personales de Jennifer Reeves -acicaladas con juegos pictóricos de luminiscencias vistosas - y las instalaciones y performances de Jennifer West -con su devoción por la participación colectiva y la inclinación hacia la documentación de las acciones-son ejemplos de prácticas fílmicas dispares que investigan las múltiples opciones de un cine hecho a mano tanto en proyecciones de festivales como en centros de arte $^{3}$. 


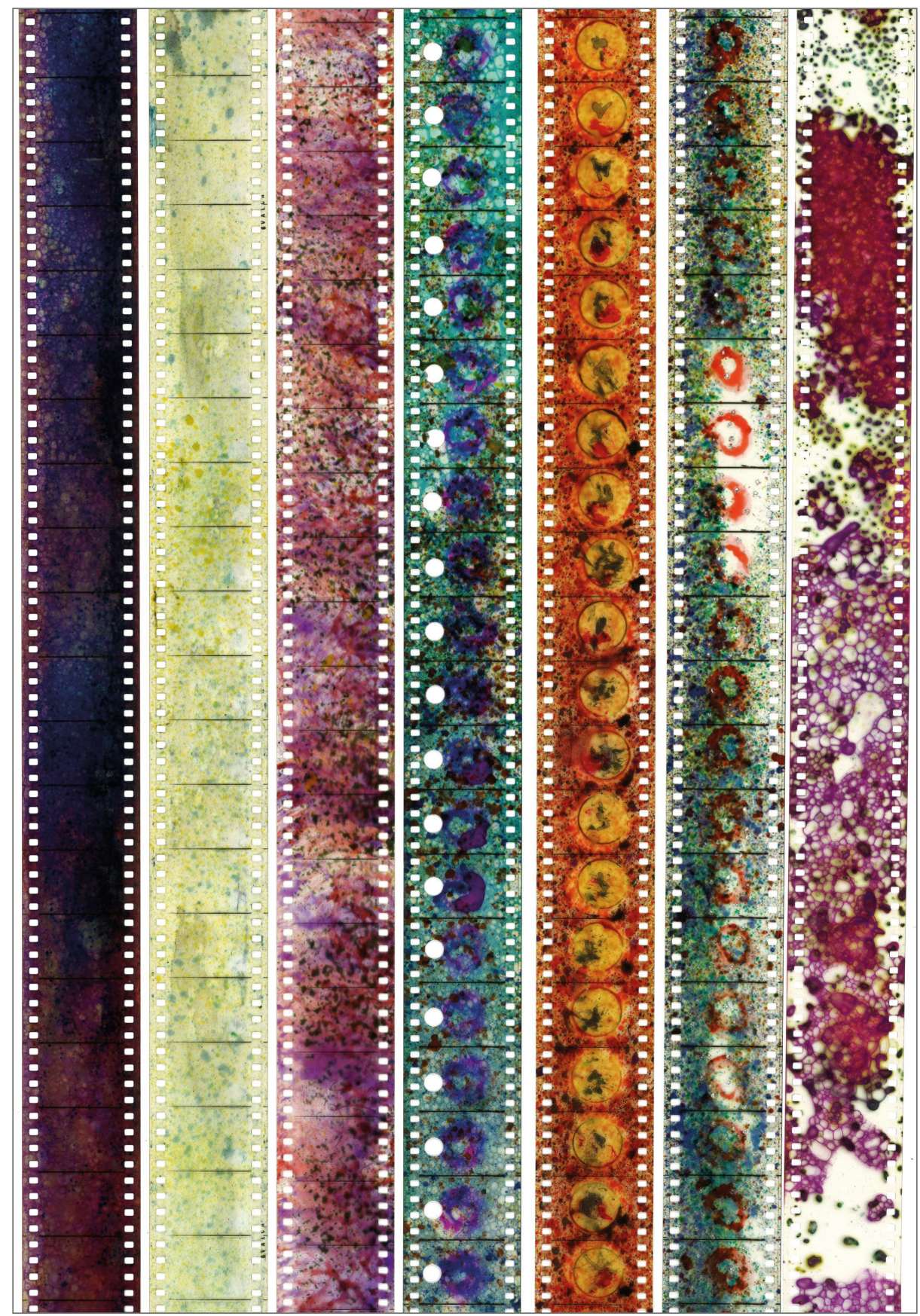

Fig. 1. Ere erera baleibu icik subua aruaren... (1970) de José Antonio Sistiaga. 
Títulos de crédito de largometrajes de ficción -como los realizados por Kyle Cooper para la película Seven (David Fincher, 1995) o los manipulados por Oscar Wright y Richard Kenworthy para Scott Pilgrim (Edgar Wright, 2010)son ejemplos de producciones pragmáticas encargadas por la industria del cine. De todos modos la naturaleza lo-fi del cine sin cámara, su carácter espontáneo y desenfadado, se corresponde más fácilmente con el audiovisual más independiente y alternativo ${ }^{4}$.

\section{¿CÓMO SE ENSEÑA CINE SIN CÁMARA?}

Como evidencia la publicación colectiva Recipes for disaster -editada por la cineasta y animadora Helen Hill (2004) gracias a una beca de la Canada Council for the Arts- el cine sin cámara es una práctica generalmente autodidacta. En esta compilación epistolar generada por un buen número de cineastas canadienses se pueden leer decenas de recomendaciones caseras y procesos intuitivos solucionados manualmente. Esta recopilación de textos, dibujos, postales, cartas manuscritas, listados mecanografiados, esbozos y diagramas, mantiene una estética desenfadada acorde con los presupuestos del DIY (do it yourself). En ella se incluyen colaboraciones de artistas reconocidas del cine experimental como Amy Lockhart, Jen Proctor o Naomi Uman. Este manual, diseñado como un elogio de la animación directa de texturas abstractas y errores fotoquímicos, defiende cómo este ámbito debe encararse desde el asombro. Habitualmente se aprende a través de la experiencia directa con los materiales en talleres, seminarios, cursos y workshops ofertados por laboratorios independientes y centros autogestionados ${ }^{5}$.

Impartir materias universitarias que incorporen el estudio del cine sin cámara desde la teoría y la práctica es un ejercicio que demuestra la herencia de la historia del cine. Contribuye a generar discursos críticos que interroguen las imágenes digitales y su ubicuidad en las pantallas actuales. Recordar la materialidad del cine, enfatizando su poder objetual ayuda a remarcar el carácter artístico del llamado séptimo arte. Es un terreno que fomenta tanto una práctica artística subjetiva como el desarrollo de proyectos ligados al cine de animación de ficción, videoclips, anuncios publicitarios u otros productos audiovisuales de factura profesional. 


\section{¿QUÉ CONTENIDOS DESARROLLAN QUIENES ENSEÑAN CINE SIN CÁMARA?}

En el ámbito español, las personas que se han dedicado meticulosamente a la enseñanza universitaria del cine sin cámara, también coordinan talleres similares en otros espacios artísticos auto-gestionados o en centros de arte que apuestan por el audiovisual más heterodoxo. Generalmente el profesorado que transmite a sus alumnos la riqueza del cine sin cámara empieza explicando su amplia tradición a lo largo de la historia. El País Vasco (Unsain 1983), Valencia y Catalunya (Martos \& De la Rosa 1999) son tres de los núcleos de la tradición experimental de la animación. Profundizar sobre algunas figuras clave mediante visionados sirve para plantear una serie de prácticas conjuntas o individuales. Es indudable que la difusión de este cine demanda un carácter empírico, una investigación directa sobre los materiales fílmicos. A menudo estos ejercicios se proyectan al final de las sesiones. Veamos los razonamientos de sus ponentes.

Esperanza Collado es una de las estudiosas de las prácticas fílmicas experimentales que también ha elaborado su propia trayectoria artística. Durante la reformulación de su tesis doctoral organiza seminarios en la Facultad de Bellas Artes de Cuenca sobre "la desmaterialización del cine en las prácticas artísticas" (Collado 2012). Después de ver las primeras reacciones entusiastas de sus alumnos empieza un taller-laboratorio titulado $Y$ ahora que Mallarmé ha muerto, tiremos los dados sobre la noción de cine que ya ha impartido cuatro veces. Respecto a la universidad la cineasta e investigadora analiza:

El curso de cine sin cámara que coordino se plantea como «aproximación plástica al material fílmico». La asignatura se llama Cine experimental y es teórico-práctica. Hacemos un repaso de trabajos de found footage más históricos, pero también películas realizadas sin cámara, en línea con los experimentos de laboratorio de Bill Brand o intervenciones directas sobre celuloide virgen. Cuando descubren a Brakhage es siempre muy revelador para los estudiantes. Mothlight y sus películas pintadas despiertan mucho interés (...) Hacemos ejercicios colectivos, primeramente. Es una primera toma de contacto con el material fílmico. Les muestro algunas películas en $16 \mathrm{~mm}$, las proyectamos y luego les enseño cómo usar la empalmadora. También les invito a blanquear película; hablo de algunos aspectos técnicos, de cómo empalmar pelí- 
cula e intervenirla. Normalmente proyectamos los resultados en la misma clase, al final de la sesión ${ }^{6}$.
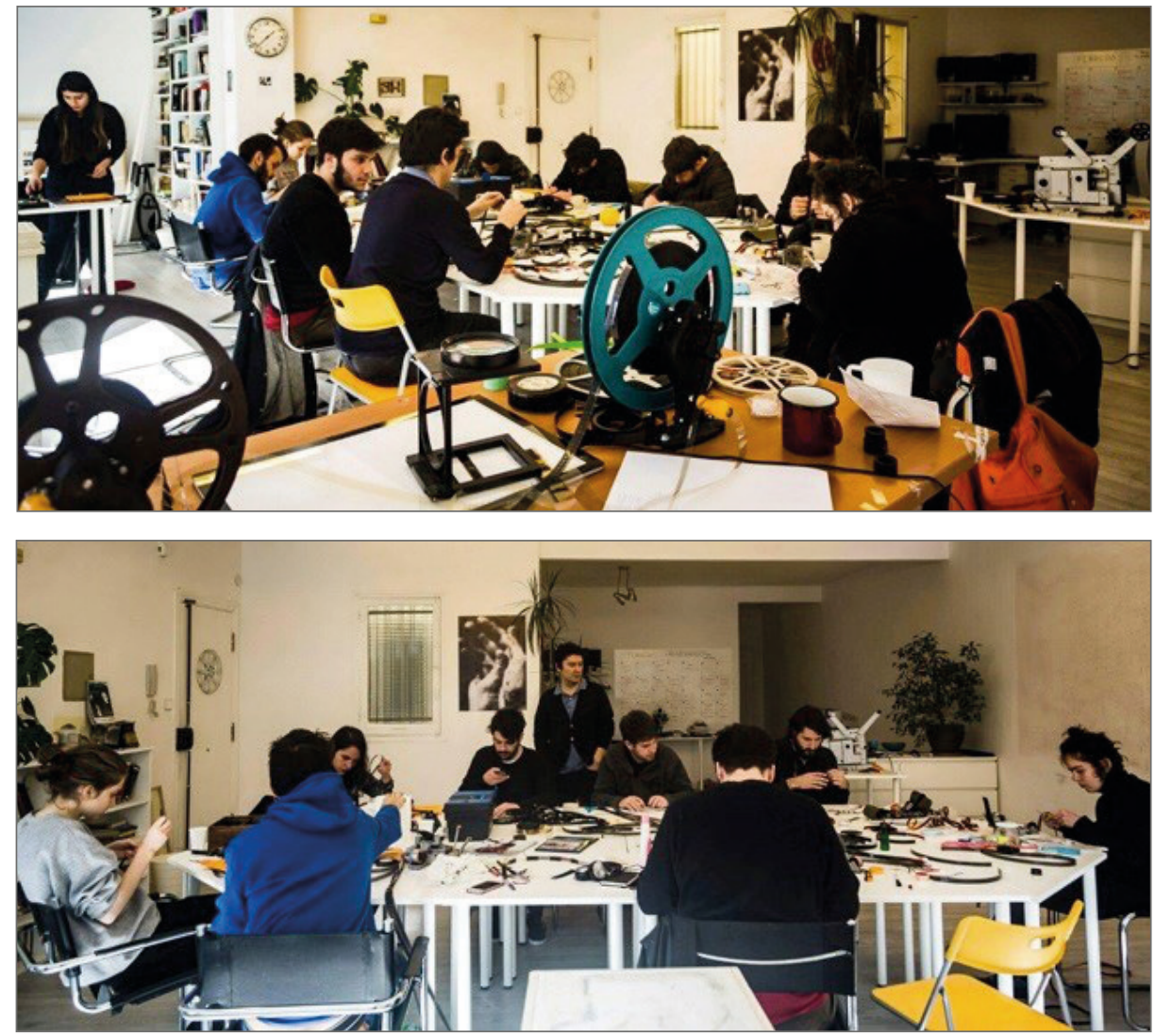

Fig. 2. Alberto Cabrera Bernal en el Master LAV de Madrid.

El cineasta madrileño Alberto Cabrera Bernal es especialista en la creación de películas de apropiación remontadas bajo estructuras sistemáticas derivadas del cine estructural. En 2013 coedita el libro y el DVD Angular sobre cine experimental internacional (Alcoz \& Cabrera Bernal 2013). Desde 2014 es profesor en escuelas de cine como TAI y el Máster LAV, ambos de Madrid (Fig. 2 y 3 ). Alberto explica sus planteamientos en los siguientes términos:

Dentro de los contenidos que trato en mi asignatura del Grado en Cinematografía y Artes Visuales, siempre incluyo un espacio para el cine sin cámara (...) Ponerles en contacto con película en el formato que sea (Súper $8,16 \mathrm{~mm}, 35 \mathrm{~mm}$ o $70 \mathrm{~mm}$ ), pensando 
entonces el cine de un modo diferente a partir de herramientas e instrumental que ellos prácticamente desconocen, lo viven como un descubrimiento y un aliciente formidables. Los alumnos valoran estos talleres de una forma muy agradecida. Este año, entre los proyectos finales de la asignatura, los alumnos tenían la posibilidad de desarrollar una pieza utilizando material de archivo. Organizados en grupos de cuatro o de cinco, han sido varios los trabajos que han salido dedicados a la apropiación y el remontaje. (...) Sería bueno que los alumnos entiendan la expresión artística, al margen de sus disciplinas, como una vía de conocimiento más allá de su utilidad concreta; soy consciente de que algunos cursan estos estudios reglados, en el contexto académico de la universidad con la idea de acceder después a un mercado audiovisual concreto, el de la publicidad o la televisión, por ejemplo, y que sus intereses son plurales y diferentes entre sí. No se trata entonces de que salgan dedicándose a hacer películas que podríamos asociar a la vanguardia, sino de descubrirles un modo más libre de pensar el medio ${ }^{7}$.

Laura Ginés es una cineasta estrechamente vinculada al cine de animación experimental. Su trayectoria artística se da a conocer a través del colectivo Laboratorium. Desde 2012 co-dirige A Home In Progress Film, un proyecto educativo independiente de cine de animación. Ginés ha desarrollado una fructífera obra que demuestra un profundo conocimiento de las diversas técnicas de animación empleadas a lo largo de la historia. Sus películas se han proyectado en centros como la Cinemàteque de San Francisco, el Anthology Film Archives of Nueva York y el MNCARS de Madrid. A nivel pedagógico imparte materias audiovisuales en ELISAVA de Barcelona:

Lo incorporo como workshops autónomos dentro de asignaturas de lenguaje audiovisual o de comunicación de proyectos de diseño. Visitamos el Arxiu Xcèntric del CCCB y en la siguiente clase manipulamos un fragmento de celuloide en un espacio distinto al del aula habitual (con ordenadores). Enfrentarse a un material o soporte nuevos les aleja de las metodologías a las que están habituados. El objetivo final es siempre un clip de vídeo digitalizado y sonorizado. Una vez han manipulado un fragmento de unos tres segundos de metraje, lo escanean y lo montan en vídeo digital. En esta digitalización pueden sumar su fragmento al de algún otro compañero. Deben sonorizarlo para convertirlo en algo 
no pretendido por el autor original de las imágenes, y pueden aplicar toda la postproducción que quieran ${ }^{8}$.

Marcel Pié es un cineasta especializado en la animación y miembro fundador de Estampa, un colectivo artístico que investiga temas audiovisuales y cuestiones vinculadas al pensamiento contemporáneo y las nuevas tecnologías. En sus clases de la Facultad de Bellas Artes de la UB y La Massana de Barcelona introduce referentes históricos del cine sin cámara para iniciar ejercicios prácticos con un alumnado que se enfrenta por primera vez a estas herramientas fílmicas:

Les muestro películas de Len Lye, Norman McLaren y Stan Brakhage. En las clases de animación lo explico en tanto que técnica y en la asignatura de proyectos en el contexto de la influencia del cine experimental y de vanguardia en el ámbito de las artes visuales y como una aproximación a la génesis del cine y de la obra en tanto que tiempo y espacio cambiante. Hacemos un pequeño ejercicio sobre un rollo de papel de máquina registradora de unos $6 \mathrm{~cm}$ de anchura. Normalmente se proyecta durante la exposición final de los trabajos. Enseño el cine sin cámara como técnica, como recurso y como forma para desarrollar proyectos más metalingüísticos que se refieren al soporte, a la luz esculpida, etc. ${ }^{9}$.

La dificultad para establecer una taxonomía específica que clasifique las diferentes manipulaciones a las que se puede someter la película y el hecho de que cualquier producto químico, líquido y alimenticio pueda modificar sorpresivamente su superficie, facilita considerar el cine sin cámara como un género abierto a la experimentación. Si Steven Woloshen (2015) ha descrito pormenorizadamente la aproximación práctica de este cine, Gregory Zinman (2019) lo ha analizado desde su poso teórico y conceptual. Ambas posturas -el ejercicio manual y la especulación analítica- pueden entreverse en los planteamientos de las materias de los cuatro profesores interrogados. 


\section{CONCLUSIONES}

Las personas consultadas tienen un amplio bagaje sobre la materia fílmica. Este les permite elaborar ejercicios prácticos considerando el trasfondo teórico derivado de su articulación. En función de las diferentes inquietudes del profesorado, la enseñanza del cine sin cámara se encamina más hacia una formulación sobre las posibilidades analógicas de la animación o hacia terrenos que implican el pensamiento fílmico y la elucubración teórica. Mostrar experimentaciones visuales hechas a mano permite despertar la curiosidad de los alumnos respecto al potencial estético de un medio tecnológico que recoge la herencia de la tradición pictórica y las artes gráficas. La universidad es pues un marco excelente para descubrir la grandeza del medio cinematográfico a unos alumnos desconocedores de su dispositivo analógico.

La destreza manual con el dibujo y la habilidad con las herramientas pictóricas son, junto a la capacidad de conceptualización, algunas de las habilidades que se activan durante las prácticas de cine sin cámara. A estas consideraciones táctiles derivadas del trabajo artesanal se le suma un proceso de experimentación plenamente conectado con la esencia fílmica. En un momento en el que los nuevos medios se alejan progresivamente de lo fílmico resulta esencial acercarse al celuloide para profundizar en sus posibilidades artísticas. El cine sin cámara representa así un ámbito audiovisual donde la percepción visual y la auditiva conectan con el sentido del tacto. En la práctica del cine hecho a mano la manipulación física de los fotogramas fomenta vislumbrar su despliegue final en pantalla. Comprobar cómo las formas plásticas elaboradas sobre la emulsión se transforman en un frenesí luminoso de imágenes en movimiento es uno de los mayores asombros derivados de estas prácticas.

Aprender colectivamente la materia básica del arte cinematográfico, recuperando celuloide en desuso de bajo coste, es una operación de reciclaje que implica el hecho de sentirse parte de un grupo con intereses afines. Este es un cine versátil que reivindica un retorno a lo objetual. Propone un trabajo manual de resultados inmediatos, con una amplia gama de opciones, entre las que se encuentra "sostener película como si fuera un lienzo de celuloide en vez de un frágil contenedor de imágenes" (Hill 2004, 4). Es una aproximación que despliega conocimiento de modo grupal, atesorando operaciones estéticas aún por desvelar. 


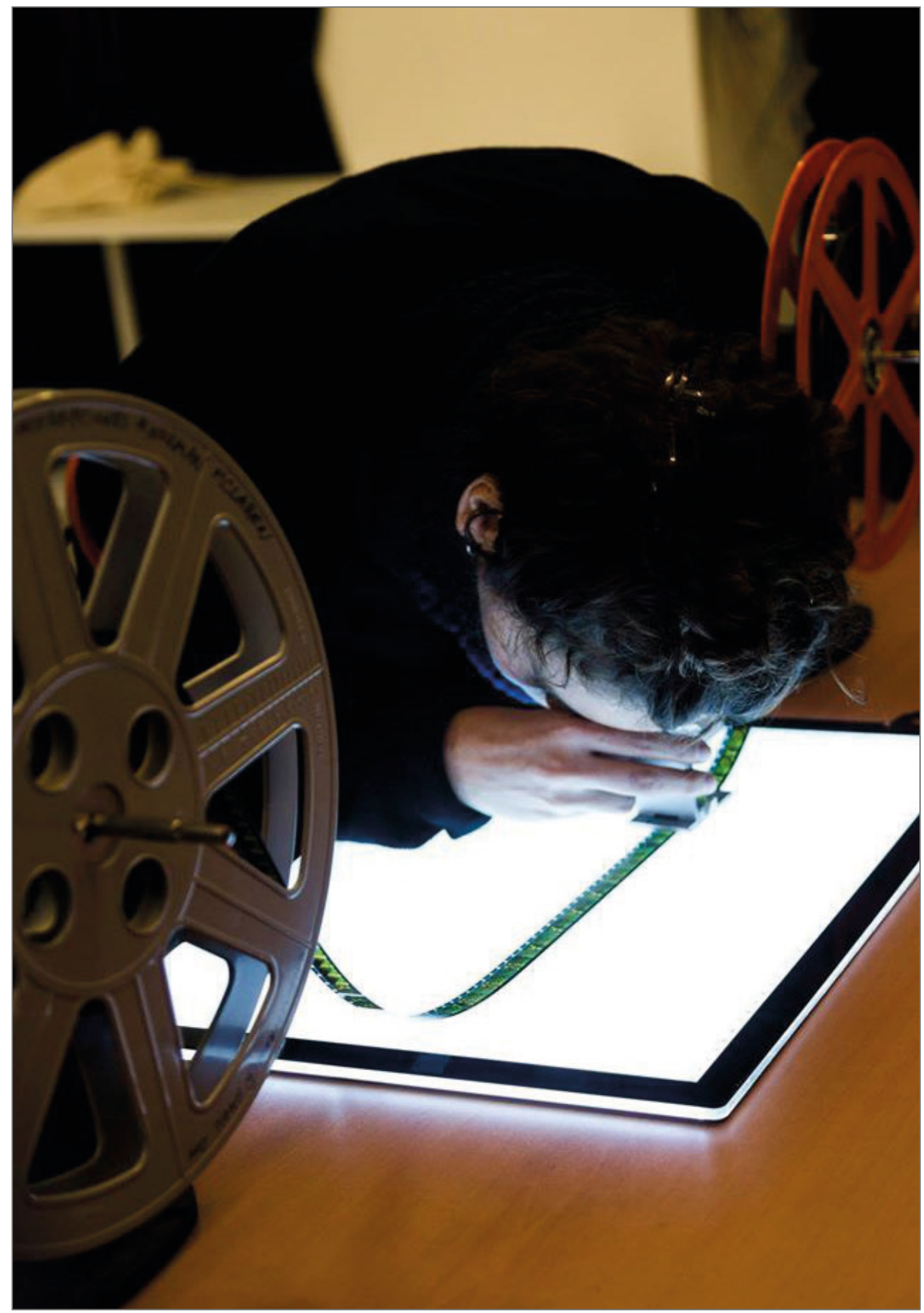

Fig. 3. Estudiante del Master LAV de Madrid observando fotogramas en una mesa de luz. 


\section{Referencias bibliográfícas}

Alcoz, Albert \& Alberto Cabrera Bernal. 2013. Angular: Cine experimental y videocreación. Cineastas, Stephen Broomer et al. Barcelona: Angular. 1 libro + DVD, 122 min.

Artigas Candela, Jordi. 1990. "Cine de animación experimental en España". En Las vanguardias artísticas en la historia del cine español, III Congreso de la AEHC-Asociación Española de Historiadores del Cine; Joaquim Romaguera i Ramió, Peio Aldazabal Bardaji \& Milagros Aldazabal Sergio, eds, 133-72. San Sebastián: Filmoteca Vasca

Bakedano Sarrionaindia, José Julián. 1987. Norman McLaren: Obra completa 1932-1985. Bilbao: Museo de Bellas Artes de Bilbao

Brougher, Kerry, Jeremy Strick, Ari Wiseman \& Judith K. Zilczer, eds. 2005. Visual music: Synaesthesia in art and music since 1900. New York: Thames \& Hudson

Collado Sánchez, Esperanza. 2012. Paracinema: La desmaterialización del cine en las prácticas artísticas. Madrid: Trama

Furniss, Maureen. [1998] 2014. Art in motion: Animation aesthetics. Bloomington IN: John Libbey

Hill, Helen, ed. 2004. Recipes for disaster: A handcrafted films cookbooklet. New Orleans LA: Helen Hill

Martos Martinez, Eladi \& Emilio de la Rosa Paredes. 1999. Cine de animación experimental en Cataluña y Valencia: La curiosidad de la experimentación. Valencia: Filmoteca de la Generalitat Valenciana

Russett, Robert \& Cecile Starr. 1976. Experimental animation: Origins of a new art. Nueva York: Da Capo

Schlicht, Esther \& Max Hollein, eds. 2010. Zelluloid: Film ohne Kamera. Anlässlich der Ausstellung, Schirn-Kunsthalle Frankfurt 2. Juni - 29. August. Bielefeld: Kerber

Unsain Azpiroz, José María. 1983. "Los vascos y el cine experimental”. Cuadernos de sección: Artes Plásticas y Monumentales 2

Woloshen, Steven. 2015. Scratch, crackle \& pop! Montreal QC: Scratchatopia

Zinman, Gregory. 2019. Making images move: Handmade cinema and the other arts. Oakland CA: University of California

Notas

${ }^{1}$ Al margen del cine de animación directa aplicada al reciclaje audiovisual existe la posibilidad de recuperar materiales fílmicos pretéritos, no originales, y manipularlos a partir de recursos fotoquímicos como el copiado por contacto de áreas específicas -Peter Tscherkassky y su laborioso proceso de creación fotoquímico centrada en la apropiación de fragmentos fílmicos ajenos emulsionados sobre película virgen a través de un puntero de luz-, con la copiadora óptica -Martin Arnold y sus insistentes juegos de avance y retroceso de conjuntos de fotogramas de películas de ficción-o mediante la digitalización ralentizada de copias de inicios del siglo XX -Bill Morrison y sus majestuosas construcciones de emulsión en proceso de descomposición. 
2 Para un análisis pormenorizado de la tradición del cine sin cámara dentro del cine de animación, el cine estructural y otras tendencias de la experimentación se recomienda consultar el libro Experimental Animation (Russett \& Starr 1976), uno de los principales estudios en recoger información sobre la obra de Norman McLaren, Len Lye, Harry Smith, Tony Conrad, Paul Sharits y Barry Spinello, entre otros.

${ }^{3}$ Para profundizar sobre algunos de los máximos referentes históricos del cine sin cámara y el despliegue de sus obras dentro del contexto artístico consultar el catálogo de la exposición Zelluloid (Schlicht \& Hollein 2010).

${ }^{4}$ No es casualidad que muchas bandas musicales ligadas al indie-rock y el pop independiente se acerquen a estas estrategias para promocionar sus nuevos temas musicales mediante videoclips alterados a mano. Grupos como Pussy Galore, Flaming Lips y Mercury Rev serían algunos de estos ejemplos.

${ }^{5}$ Valgan como ejemplo los diferentes cursos de cine sin cámara que anualmente se organizan en espacios consolidados de la experimentación fílmica como la escuela Mono No Aware de Nueva York, la Film Farm dirigida por Philip Hoffman, los laboratorios LaborBerlin de Berlín, l'Etna i l'Abominable de París, no.w.here de Londres o el Master Lav de Madrid.

${ }^{6}$ Esperanza Collado Sánchez, correo electrónico al autor, 13 feb. 2020.

${ }^{7}$ Alberto Cabrera Bernal, correo electrónico al autor, 20 feb. 2020.

${ }^{8}$ Laura Gines Bataller correo electrónico al autor, 14 feb. 2020.

${ }^{9}$ Marcel Pié Barba, correo electrónico al autor, 13 feb. 2020. 